\title{
Sebaceous Adenoma
}

National Cancer Institute

\section{Source}

National Cancer Institute. Sebaceous Adenoma. NCI Thesaurus. Code C4174.

A benign, well circumscribed neoplasm arising from the sebaceous glands. It usually presents as a small yellowish tumor in the sun exposed skin of head and neck. It is characterized by the presence of sebaceous cells aggregates with a peripheral rim of basaloid cells. 